\title{
Effect of Question Structure on College Students' Electronic Reflection Outcomes: A Case Study
}

\author{
Pao-Nan Chou \\ Department of Education \\ 33, Sec. 2, Shu-Lin St., Tainan 700, Taiwan \\ Tel: 886-6-2133111 ext. 974 E-mail: pnchou@mail.nutn.edu.tw
}

Accepted: February 16, 2012 Published: March 24, 2012

Doi:10.5296/ijld.v2i2.1400ＵRL: http://dx.doi.org/10.5296/ijld.v2i2.1400

\begin{abstract}
This study aims to design different types of reflection questions to support college students' electronic reflection. Whether or not the reflection question structure may influence students' reflection outcomes is the research focus. According to various cognitive learning concepts, three types of reflection questions, which include surface, medium and deep questions, are designed and implemented in three weeks of the class. Forty college students majoring in instructional technology participated in this study. The results of the qualitative analysis showed that the surface reflection question yields swallow reflection works, and the medium and deep reflection questions allow students to produce meaningful reflection contents. The results of the quantitative analysis showed that the medium and deep reflection questions are better than the surface reflection question in terms of critical thinking. However, no significant difference is found between the medium and deep reflection questions.
\end{abstract}

Keywords: Cognitive learning, Electronic reflection, Qualitative study, Question structure, Learning performance

\section{Introduction}

In recent years, under the trend of information and communication technologies in education, traditional paper reflection has been replaced by electronic reflection, which is often embedded in online learning systems (Howland et al., 2011). The mechanism of the electronic reflection in the systems allows students to upload reflection files or to use notebook tools to write online reflections (Chang, 2001). For example, Chou and Chen (2008) asked college students to upload reflection files to the wiki learning system. In Chang and Chou's (2011) study, high school students were required to write online reflections by using notebook tools in the web-based learning system. 
Regarding the use of electronic reflection in the existing literature, previous studies tended to focus on the relationship between technology use and students' reflection performances or between students' reflection behaviors and learning outcomes, and ignore the design of the reflection questions. Linn (2000) reported that one technology tool in the learning system significantly supported students' electronic reflection skills. However, the author did not specifically mention the structure of the reflection questions. Chang and Chou (2011) found that various reflection contents written in the online learning system would not affect students' learning outcomes. However, authors also did not mention the design of the reflection questions.

The main idea of the design of the reflection questions is to allow course instructors to develop the structure of the reflection questions (King, 1990) which guide students toward correct reflective thinking (Lin et al., 1999). Of previous related studies, King (1991) designed three types of reflection questions: planning, monitoring, and evaluating -to support students' math solving abilities; Lin and Lehman (1999) designed three types of reflection : meta-cognitive, cognitive, and motivation-to enhance college students' problem solving skills. However, in both studies discussed above, the research was conducted in the traditional learning environments where students completed paper reflections.

Different from previous research, the electronic reflection strategies the current study adopts is the design of the reflection questions. Rather than concentrating on students' reflection behaviors or computer-assisted reflection tools, the study aims to explore the relationship between reflection question structures and students' learning performances. Whether or not the reflection question structure may influence students' reflection outcomes is the research focus.

\section{Theoretical Discussion}

\subsection{Electronic Reflection}

The concept of the electronic reflection is to combine available information technologies with traditional reflection learning, which only allows students to reflect their thinking in the paper-form documents. In the current trend of the electronic reflection, students can use online tools, such as web-based notebook, or upload reflection files into online systems to complete electronic reflection assignments (Howland et al., 2011). For instance, in Chang and Chou's (2011) study, instructors asked students to employ an embedded online tool to create reflection files. In Chou and Chen's (2008) study, students should upload reflection files into the wiki platform system. In the current study, due to the limit of the teaching environment for the course instructor, instead of using online tools, research participants only uploaded their digital reflection files into one online learning system called E-Course.

\subsection{In-Cass Electronic Reflection}

In the existing literature, previous studies all focused on after-class electronic reflection (e.g. Chou \& Chen, 2008; Chang \& Chou, 2011; Linn, 2000). In other words, students are asked to create electronic reflections after the course instruction and activity is completed. The drawback of this teaching model is that students only use limited memory power to reflect their thinking after backing to their residential houses or dormitories. Different from 
previous research, this study proposes an in-class electronic reflection model according to two theoretical foundations:

1. Information processing theory: According to Atkinson and Shiffrin's (1968) study, since the short-term memory has limited size, effective teaching methods must be used to transfer information stored in the short-term memory to the long-term memory, which own limitless size. After the instructor impart knowledge to students, the in-class electronic reflection model can serve as a better channel (teaching method), which allows student to instantly reflect what they learned (information in the short-term memory) in the classroom and then to store meaningful information into their learning minds (existing knowledge base in the long-term memory).

2. Application principle: According to Merrill (2009)'s first principle of instruction, five important instructional elements, which include demonstration, application, task-centered, activation, and integration principles, may yield meaningful learning outcomes. By borrowing Merrill's application principle, the in-class electronic reflection model assumes that the instant reflection in the classroom can allow students to apply what they learned into their thinking models. In such way, students can practice course contents by linking their old learning experiences.

\subsection{Design of Reflection Question}

Based on two instructional theories, this study adopts a structure-based strategy to design reflection questions:

1. Coaching skills: Jonassen(1999) contended that teachers should constantly provide coaching skills to guide students toward a logical thinking way in the constructive learning environment. For example, as students encounter difficult math problems, one of the coaching skills the instructor can provide is to use hint strategy to indirectly guide students toward right solving procedures.

2. Conceptual scaffolds: Hill and Hannafin (2001) argued that teachers must provide different types of scaffolds to decrease students' cognitive learning loads. The conceptual scaffolds can be used to support learners in acquiring course knowledge. For instance, when students engage in a problem-solving task, one teacher-provided solution, which facilitates students' solving construction, can be a conceptual scaffold.

According to different cognitive thinking structures (from lower to higher order thinking), this study designs three types of reflection questions: surface, medium, and deep reflection learning. These three reflection questions serve as coaching skills and conceptual scaffolds, which support students' reflection learning. 


\section{Research Design}

\section{3-1 Research Method}

The current study aims to explore students' learning performances under different reflection learning questions. The study adopts Stake's (2005) simple case study method to observe students' reflection works. The simple case in the study is the one course taught in a teaching-based university in Taiwan. The observation focus is the instructional benefit of three types of reflection questions under which students respond to different learning performances. The research structure of the study is depicted in Figure 1.

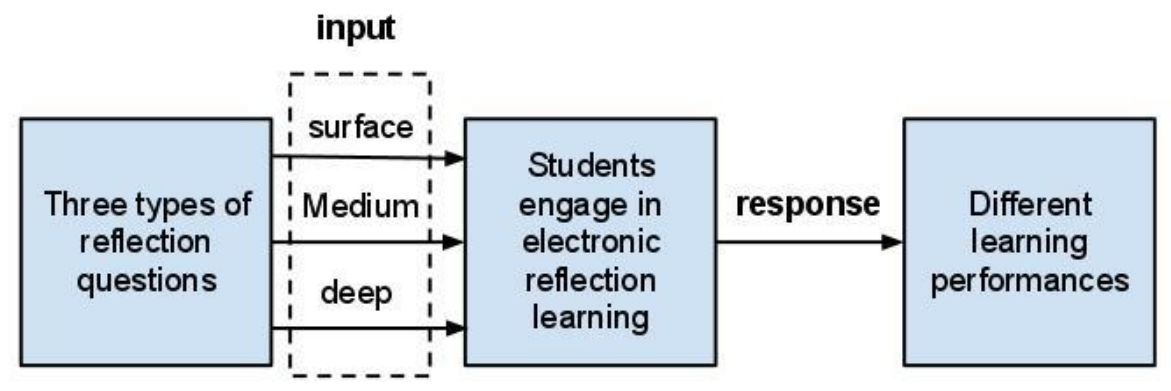

Figure 1 This study's research structure

According to various cognitive learning concepts, three types of reflection questions are designed as the following:

1. Surface reflection questions (lower-order thinking): Based on your past or recent TV watching experiences, can you identify inappropriate or controversial contents appeared in the variety shows?

2. Medium reflection questions (between lower-order and higher-order thinking): Based on your past or recent TV watching experiences, can you indicate your favorite and disliked contents appeared in the TV commercials? Please propose your improvement ideas for the disliked contents.

3. Deep reflection questions (higher-order thinking): Based on your past or recent TV watching experiences, please use the following three elements to discuss your favorite cartoon programs: (a) cartoon contents' ideology, (b) cartoon characters' behaviors, and (c) cartoon rating's (rating system) perspective.

The surface reflection question allows students to identify the fact-based knowledge. Critical viewpoints are not required for students' reflection contents. The medium reflection question, whose cognitive level is higher than the surface's, not only asks students to discuss the pros and cons of the TV knowledge, but also require students to propose their improvement suggestions. The deep reflection question lists three critical discussion points on which students should respond related answers. 


\section{3-2 Research Subject}

Forty college students majoring in instructional technology participated in this study. 73 percent of the research participants were female students; 27 percent of students were male. These students registered the course "Media Literacy Education" in the 2010 fall semester. Compared to other department students, the research subjects' informational technology literacy and learning motivation exceeded the average performance level. Since participants were required to write electronic reflections in the classroom, the course instructor surveyed students' computer typing skills in the first week of the class. The results showed that students' self-perceived typing skills were extremely well.

\section{3-3 Research Procedure}

The "Media Literacy Education" is a two-credit elective course offered in the department of education at a southern Taiwan university. The learning environment of the course occurs in the computer lab. Each student can use one individual computer in the classroom. Each week's course planning is arranged into two parts: 70 minutes of teacher-dominated instruction and 30 minutes of students' electronic reflection learning.

Three types of reflection questions were implemented in three weeks of the class. According to each week's course topic, the instructor posted one reflection question in the online discussion board each week. During electronic reflection learning, students wrote at least 300 words in their reflection contents by using Word application. Within 30 minutes, students uploaded the reflection files to one online learning system. The system will lock the "upload function" if students do not submit their files after 30 minutes.

\section{3-4 Data Analysis}

This study employed a mixed approach to collect related data. The qualitative observation method was used to examine the contents of students' reflection works. One research assistant, whose educational background is Chinese literature and the principal investigator collaboratively analyzed reflection files. According to the quality of the reflection contents, three levels of works were created: low, medium, and high. After qualitative analysis, the quantitative statistical method (chi-square) was used to test whether a significant difference existed in three levels of reflection contents.

\section{3-5 Reliability Check}

The qualitative analysis often contains researchers' subjective perspectives. In order to ensure data consistency, the Krippendorff's alpha (Neuendorf, 2002) was used to verify two observers' analyzed documents. The reliability check showed that qualitative analysis's alpha coefficient is 0.85 . In other words, there was a higher agreement $(85 \%)$ between the research assistant and the principal investigator. As for 15 percent of disagreements, one post-doctoral researcher was hired to double-check the controversial parts. 


\section{1l Macrothink}

\section{Results}

\section{5-1 Qualitative Results}

\section{5-1-1 Learning performances under surface reflection question}

Since the surface reflection question does not list several limits (fact-identification only), students are expected to write other discussion points related to the question. However, under this open-end question, students tended to reflect unrelated knowledge and ignore the meaning of the question. Most of the reflection contents were unorganized information from students' past living experiences. For example, students might analyze why some variety shows attracted audiences' attentions.

\section{5-1-2 Learning performances under medium reflection question}

The medium reflection question contains more limits, including the pros and cons of the fact-identification and further explanations on the disliked contents. Under this thinking model, students are expected to post higher-order discussions regarding the improvement suggestions. Examining the students' reflection works showed that most students responded related information and solutions for the question's requirement. However, some students focused on the lengthy descriptions of the favorite and disliked contents. Overall, the medium reflection question can serves as an instructional scaffold to support students' thinking process toward a meaningful reflection.

\section{5-1-3 Learning performances under deep reflection question}

The cognitive structure of the deep reflection question is more complex than other two reflection questions'. Three critical elements limit students' reflection scopes in which direct related responses to the question are required. However, the qualitative analysis shows that a polarized reaction exits in students' reflection works. Almost half of students grasped the meaning of the question and reflected logical thinking contents. More than 30 percent of students did not put a deep insight into the question's requirement. Several students circumvented the question's rule and concentrated on unrelated information. For example, students analyzed cartoons' contents from violence and pornography's perspectives.

\section{5-2 Quantitative Results}

This study quantifies the qualitative data by counting students' different performances under three types of reflection questions. Table 1 shows the quantitative results. 
Table 1 Results of Quantitative Analysis

\begin{tabular}{|c|c|c|c|}
\hline $\begin{array}{l}\text { R } \\
\text { Quality } \\
\text { Reflection } \\
\text { Question }\end{array}$ & Low & Medium & High \\
\hline Surface & 21 & 13 & 6 \\
\hline Medium & 4 & 11 & 25 \\
\hline Deep & 6 & 15 & 19 \\
\hline
\end{tabular}

From the information shown in Table 1, students under the medium reflection question can produce high quality of reflection contents. Since the data between the medium and deep reflection question is extremely closed, an inferential statistical technique is needed to compare the differences of the instructional effectiveness among three types of reflection questions. Table 2 summaries the analytical results of Chi-Square.

Table 2 Results of Chi-Square Analysis

\begin{tabular}{llll}
\hline Comparison Item & df & $\mathrm{X}^{2}$ & $\mathrm{p}$ \\
\hline $\begin{array}{l}\text { Surface,medium and } \\
\text { deep }\end{array}$ & 4 & 31.21 & $0.00^{* *}$ \\
Medium and deep & 2 & 2.02 & 0.36 \\
\hline
\end{tabular}

$* * \mathrm{p}<0.01$

The information in Table 2 shows that there is a significant difference on students' learning performance for three types of reflection questions $\left(X^{2}=31.21, p<0.01\right)$. Compared to the surface reflection question, the medium and deep reflection questions can allow students to write more meaningful reflection works. However, no significant difference exists between the medium and deep reflection questions for students' learning performances $\left(\mathrm{X}^{2}=2.02\right.$, $\mathrm{p}=0.36>0.01$ ). In other words, the instructional effectiveness of both reflection questions is the same.

\section{Discussion \& Conclusion}

The purpose of the study is to explore the effect of question structure on students' electronic reflection outcomes. The results of the qualitative analysis indicate that students perform 
different reflection responses while receiving three types of reflection questions. The results of the quantitative analysis report that under the medium and deep reflection questions, students can produce high quality of reflection contents. Figure 2 is a graphic representation that expresses this study's findings.

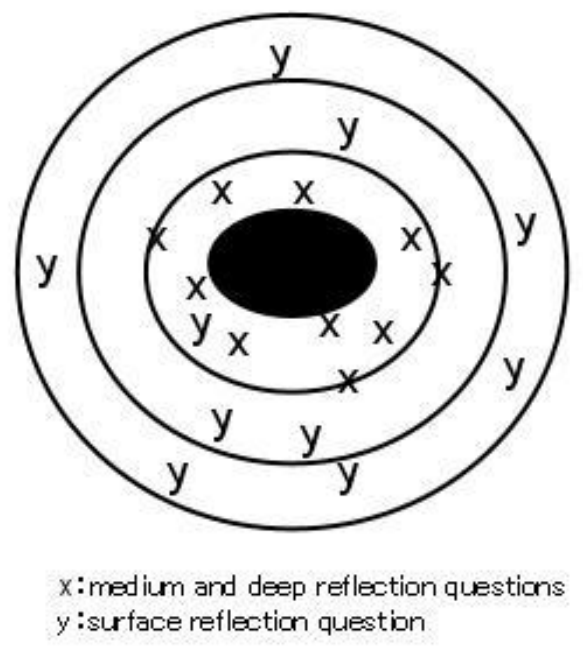

Figure 2 Conclusion of the study's findings

The target (black area) in Figure 2 is the meaningful reflection. Under the surface reflection question, most of the students miss the target and move around the circle. These students often lost their orientations since the surface reflection question does not provide several cognitive directions (few limits). However, under the medium and deep reflection questions, most of the students obtain assistance from the question design (more limits) and move toward the target. The medium and deep reflection questions seem to narrow down students' complex thinking process and allow them to focus on the questions' requirements.

The results of the current study confirm that the question-based reflection can enhance students' learning performances. The finding is consistent with King (1991) and Lin and Lehman's (1999) studies. Two instructional implications for school educators and course instructors are proposed. First, in order to avoid students' disorientations, appropriate guidelines should be provided for the reflection questions. Second, depending on students' educational backgrounds, the higher-order thinking design for the reflection questions may not yield a satisfaction result (more meaningful reflection works. 


\section{References}

Atkinson, R. C., \& Shiffrin, R. M. (1968). Human memory: A proposed system and its control processes. In K. W. Spence \& J. T. Spence (Eds.), The psychology of learning and motivation (Volume 2)(pp. 89-193). New York: Academic Press.

Chang, C.-C. (2001). Construction and evaluation of a web-based learning portfolio: An electronic authentic assessment tool. Innovations in Education and Teaching International, $38(2), 144-155$.

Chang, C. -C, \& Chou, P. -N. (2011). Effect of reflection category and reflection quality on learning outcome during web-based portfolio assessment process: a case study of high school students in computer application course. Online Turkish Journal of Educational Technology, 10(3), 101-114

Chou, P. -N. \& Chen, H. -H. (2008). Engagement in online collaborative learning: A case study using a web 2.0 tool. Journal of Online Learning and Teaching, 4 (4), 574-582.

Hill, J. R., \& Hannafin, M. J. (2001). Teaching and learning in digital environments: The resurgence of resource-based learning environments. Educational Technology Research and Development, 49(3), 37-52.

Howland, J. L., Jonassen, D., \& Rose, M. M. (2010). Meaningful learning with technology (4 ${ }^{\text {th }}$ edition). Upper Saddle River, NJ : Pearson/Merrill Prentice Hall.

Jonassen, D. (1999). Designing constructivist learning environments. In C. M. Reigeluth (Ed.). Instructional-design theories and models: A new paradigm of instructional theory (Volume II) (pp. 215-239). Mahwah, NJ: Lawrence Erlabum Associates.

King, A. (1990). Enhancing peer interaction and learning in the classroom through reciprocal questioning. American Educational Research Journal, 27(4), 664-687.

King, A. (1991). Improving lecture comprehension: Effects of a metacognitive strategy. Applied Cognitive Psychology, 5, 331-346.

Lin, X., \& Lehman, J.D. (1999). Supporting learning of variable control in a computer- based biology environment: Effects of prompting college students to reflect on their own learning, Journal of Research in Science Teaching, 36(7), 837-858.

Lin, X., Hmelo, C., Kinzer, C. K., \& Secules, T. J. (1999). Designing technology to support reflection. Educational Technology Research and Development, 47(3), 43-62.

Linn, M. C. (2000). Designing the Knowledge Integration Environment. International Journal of Science Education, 22(8), 781-796.

Merrill, M. D. (2009). First principle of instruction. In C. M. Reigeluth \& A. A. Carr-Chellman (Eds.). Instructional-design theories and models: Building a common knowledge base (pp. 41-56). New York: Taylor \& Francis.

Neuendorf, K. A. (2002). The content analysis guidebook. Thousand Oaks, CA: Sage. 


\section{Macrothink

Stake, R. (2005). Qualitative case studies. In N. Denzin \& Y. Lincoln. (Eds.). Handbook of qualitative research. (3rd edition) (pp. 443-466). Thousand Oaks, CA: Sage. 